\title{
Mixed oligopoly, public firm behavior, and free private entry
}

\author{
John Bennett ${ }^{\mathrm{a}}$, Manfredi La Manna ${ }^{\mathrm{b}, *}$ \\ a Department of Economics and Finance, and CEDI, Brunel University, Uxbridge, UB8 3PH, United Kingdom \\ ${ }^{\mathrm{b}}$ University of St. Andrews, School of Economics and Finance, St. Andrews, Fife, KY16 9AL, Scotland, United Kingdom
}

\section{A R T I C L E I N F O}

\section{Article history:}

Received 24 March 2012

Received in revised form 7 August 2012

Accepted 15 August 2012

Available online 31 August 2012

\section{JEL classification:}

H32

L32

P23

Keywords:

Mixed oligopoly

Entry

Privatization

\begin{abstract}
A B S T R A C T
We analyze a mixed oligopoly with free entry by private firms, assuming that a public firm maximizes an increasing function of output, subject to a break-even constraint. We establish an irrelevance result: whenever a mixed oligopoly is viable, then aggregate output, aggregate costs and welfare are the same with and without the public firm. However, replacing a viable mixed oligopoly with a public monopoly yields higher net welfare. Implications for privatization policy are suggested.
\end{abstract}

(c) 2012 Elsevier B.V. All rights reserved.

\section{Introduction}

In many countries, in industries such as electricity, banking, air transport, telecommunications, and postal services, public firms operate in the same markets as private ones. To analyze such markets, an extensive literature on 'mixed oligopoly' has developed, recent contributions including Ghosh and Mitra (2010) and Matsumura and Ogawa (2012). In this literature it is commonly assumed that a public firm behaves strategically to maximize either social welfare or a weighted objective function with welfare as one of the arguments, while the budget constraint is rarely considered. A different approach was taken in some early contributions. Crémer et al. (1989) assume the public firm is welfare-maximizing, but subject to a break-even constraint. Furthermore, they note that their results would still hold for a realistic 'bureaucratic' objective such as output maximization subject to this constraint, a formulation which is suggested by Estrin and de Meza (1995) to reflect behavior of public firms in practice. However, the implications of incorporating free entry by private firms into this framework have not been fully explored (though Ino and Matsumura, 2010, analyze free private entry when the public firm is welfare-maximizing). Free entry is empirically relevant, given the trend to deregulation and privatization in

\footnotetext{
* Corresponding author. Tel.: +4401334 462434.

E-mail addresses: john.bennett@brunel.ac.uk (J. Bennett), mlm@st-and.ac.uk (M. La Manna).
}

industries in which public firms operate (see Florio and Fecher, 2011) and, theoretically, it throws up some intriguing results.

In formalizing the public firm's behavior we argue that a key role is played by the profit-constraint, so much so that the public firm's maximand can take a very general form, as long as it is increasing in the public firm's own output. This maximand is general enough to cover a wide range of managerial specifications, including maximization of total revenue, output, employment, and the rate of growth of output. Compared to the objective used in most mixed oligopoly literature, this formulation is informationally less demanding to enforce, allowing decentralized decision-making.

We show that the presence of a public firm is immaterial for aggregate output and costs, and therefore for social welfare, even if the public firm has a cost disadvantage relative to private firms, provided the cost disadvantage is not too great. Several irrelevance results have already been shown in the literature on mixed oligopoly, including the demonstration by Matsumura and Kanda (2005) that, with a welfare-maximizing public firm and free entry, privatization does not affect total output or the output of each active private firm. But our irrelevance result is based on what we suggest is a more realistic formulation of public firm behavior, and it extends further-to social welfare. ${ }^{1}$

\footnotetext{
1 Our irrelevance result is entirely different from that of White (1996), who examines a model in which optimal production subsidies can be provided for private firms.
} 
Our result arises through the balance of two effects. The public firm produces at higher cost; but as it produces past the profitmaximizing level there is a negative effect on the number of private firms, and therefore on the duplication of fixed costs. For the given range of cost parameters the strong policy implication follows that there would be no welfare gain from privatization of the public firm (or indeed from nationalizing private firms). We then show, however, that for the same cost range, a monopoly public firm would yield a higher level of welfare than either of the alternatives, though we suggest that a monopoly public firm may have drawbacks in dynamic terms. However, if the cost disadvantage of the public firm is relatively large, a mixed oligopoly is not viable, while an all-private oligopoly outperforms a monopoly public firm in welfare terms.

\section{The model}

We consider a homogeneous-good oligopoly facing a linear demand function,

$P(Q)=a-Q$,

where $P($.$) is unit price and Q$ total output. The industry is populated by a public firm, indexed 0 and set $P$ of $n$ identical private firms, each indexed $p$, with all firms entertaining Cournot conjectures. We assume only one public firm because, as shown in Bennett and La Manna (2012), the industry would be unstable with more than one public firm.

The output of the public firm is $q^{0}$ and that of a private firm is $q^{p} ; Q=q^{0}+n q^{p}$. The total cost function for any firm $i$ is linear:

$C\left(q^{i}\right)=c^{i} q^{i}+k^{i}, \quad c^{i} \geq 0 ; k^{i} \geq 0, i=0, p$.

The public firm chooses output $q^{0}$ to maximize a function $G$ that is increasing in $q^{0}$, subject to a break-even constraint. Thus, it solves the program,

$\max _{q^{0}} G\left(q^{0}, \sum_{p \in P} q^{p}\right) \quad$ subject to $\pi^{0} \geq 0$

where

$\pi^{0} \equiv\left[a-c^{0}-q^{0}-\sum_{p \in P} q^{p}\right] q^{0}-k^{0}$.

The only restrictions that we impose on $G($.) are that it is wellbehaved, that the second-order conditions are satisfied, and that in equilibrium $G_{q^{o}}>0$. Denoting by $\lambda$ and $L($.) the Lagrange multiplier and Lagrangian, respectively, we obtain

$L_{q^{0}}=G_{q^{0}}+\lambda \pi_{q^{0}}^{0}=0$

$L_{\lambda}=\pi^{0}=0$.

Given that $G_{q^{0}}>0$, the break-even constraint binds, and it follows that the public firm produces past the profit-maximizing output (i.e., in equilibrium, $\pi_{q^{0}}^{0}<0$ ).

Note that the first-order condition (5) plays no role in determining the equilibrium values of the program. Rather, it is the zero-profit condition (6) that does all the work. To ensure that the public firm can satisfy its break-even constraint, we assume that it would be able to make non-negative profit as a monopolist:

$a \geq c^{0}+2 \sqrt{k^{0}}$.

As is common in the mixed oligopoly literature, and is substantiated by a large body of empirical evidence (see, e.g., Roland, 2008), we assume the public firm may have a cost disadvantage relative to a private firm. We consider two possibilities: (i) $c^{0}>c^{p}=0$ (the private firms' marginal cost being normalized to zero) and $k^{0}=k^{p}$; (ii) $c^{0}=c^{p}=0$ and $k^{0}>k^{p}$.

Each private firm solves the following program:

$\max _{q^{p}} \pi^{p}\left(q^{p}\right)=\max _{q^{p}}\left[\left(a-q^{0}-\sum_{\bar{p} \in P, \bar{p} \neq p} q^{\bar{p}}-q^{p}\right) q^{p}-k^{p}\right]$,

given the free-entry condition,

$\left[\left(a-q^{0}-\sum_{\bar{p} \in P, \bar{p} \neq p} q^{\bar{p}}-q^{p}\right)\right] q^{p}=k^{p}$.

From the first-order conditions for maximization of (8), together with (6) and (9), if there is an interior solution it is unique. Denoting interior solution values by an asterix,

$q^{0 *}=k^{0} /\left(\sqrt{k^{p}}-c^{0}\right) ; \quad q^{p *}=\sqrt{k^{p}} ;$

$n^{*}=\left[\left(a-\sqrt{k^{p}}\right)-k^{0} /\left(\sqrt{k^{p}}-c^{0}\right)\right] / \sqrt{k^{p}}$.

The condition for this equilibrium to obtain with at least one private firm may be written in terms of a non-empty interval for $c^{0}$ (or, equivalently, as a non-empty interval for $k^{0}$ ).

Lemma 1. A mixed oligopoly equilibrium exists if $c^{0} \in\left[0, \sqrt{k^{p}}-\right.$ $\left.k^{0} /\left(a-2 \sqrt{k^{p}}\right)\right]$.

The upper bound for $c^{0}$ is given by setting $n^{*} \geq 1$ in (10); the lower bound is the condition that $c^{0} \geq c^{p}=0$. From (10),

$\partial n^{*} / \partial c^{0}<0 ; \quad \partial n^{*} / \partial k^{0}<0$.

An increase in either of the public firm's cost disadvantages reduces entry. Higher cost parameters for the public firm lead it to produce more so as to break even, and the negative impact on price causes there to be less private entry.

For comparison, consider an all-private oligopoly with free entry. Denoting values in this solution with a circumflex,

$\hat{q}^{p}=\sqrt{k^{p}} ; \quad \hat{n}=\left(a-\sqrt{k^{p}}\right) / \sqrt{k^{p}}$.

From (10) and (12), $q^{0 *}+n^{*} q^{p *}=\hat{n} \hat{q}^{p}=a-\sqrt{k^{p}}$ and $c^{0} q^{0 *}$ $+k^{0}+n^{*} k^{p}=\hat{n} k^{p}=a-\sqrt{k^{p}}$. Thus we have the following 'irrelevance' result:

Proposition 1. For the functional forms (1)-(2), aggregate output, aggregate costs and net social welfare are the same in a mixed oligopoly as in an all-private oligopoly.

Despite the difference in objective functions between the public firm and private firms, aggregate output is the same in the two equilibria. Two contradictory forces drive this result. The public firm's higher costs leave it at a competitive disadvantage relative to private firms; but the public firm's maximization of a function that is increasing in its output level acts as a credible commitment to producing past its profit-maximizing point, giving the public firm a competitive advantage. In equilibrium, the powerful effects of free entry cause these two forces to balance out. It is worth noting that Estrin and de Meza (1995, Proposition 5) argue, by verbal reasoning, that (using our notation) $n^{*}+1=\hat{n}$. However, from (10) and (12), this is true only if $k^{0}=\left(\sqrt{k^{p}}-c^{0}\right) \sqrt{k^{p}}$, which can never hold if the public firm has any cost disadvantage.

Furthermore, despite the cost-function differences between the public firm and private firms, the irrelevance result also holds with respect to aggregate costs, and the immediate corollary is that it holds for net social welfare. An implication is that, at least for the canonical form sketched above, if a mixed oligopoly is viable there is no rationale for either partial nationalization (i.e., switching from an all-private oligopoly to a mixed oligopoly) 
or full privatization (i.e., switching from a mixed oligopoly to allprivate oligopoly). Note also that because private firms earn zero profits in equilibrium, the proposition would still hold if these firms were foreign owned.

However, another policy option for the government might be to prohibit private production altogether (i.e., full nationalization). Our second proposition considers the implications for social welfare. ${ }^{2}$

Proposition 2. For the functional forms (1)-(2), with free private entry (a) if a mixed oligopoly is viable (i.e., $c^{0} \in\left[0, \sqrt{k^{p}}-k^{0} /(a-\right.$ $\left.\left.2 \sqrt{k^{p}}\right)\right]$ ) a public firm monopoly is welfare-superior to a mixed oligopoly or all-private oligopoly; (b) if no private entrant could break even in the presence of a public firm (i.e., $c^{0} \in\left(\sqrt{k^{p}}-k^{0} /\left(a-2 \sqrt{k^{p}}\right)\right.$, $\left.\left.a-2 \sqrt{k^{0}}\right]\right)$ all-private oligopoly is welfare-superior to a monopoly public firm.

Proof. see Appendix.

We saw previously that for the cost range in which a mixed oligopoly is viable, at the aggregate level a mixed oligopoly merely replicates an all-private oligopoly. However, Proposition 2 specifies that, for this cost range, a monopoly public firm would generate greater welfare. Thus, it is not public firm production that causes welfare to be forgone; rather, it is public firm production together with private production that causes the problem. Our result complements the mixed oligopoly literature in which the public firm is assumed welfare-maximizing. There it is found that, with free entry, if the public firm has no cost disadvantage, privatization (or nationalization) does not affect welfare (Ino and Matsumura, 2010). With our differing assumptions, however, we specify the extent of cost-disadvantage for which nationalization is optimal.

Nonetheless, for the higher cost range in which a monopoly public firm is viable, but a mixed oligopoly is not, welfare is greater with free-entry all-private oligopoly than with a monopoly public firm. The higher cost level for the public firm rules it out as an instrument for enhancing social welfare. If $c^{0}$ is higher than the ranges specified in Proposition 2 the public firm cannot meet its break-even constraint.

\section{Conclusion}

We examine the equilibrium for a mixed oligopoly in which a public firm maximizes output subject to a break-even constraint and there is free entry by private firms. An irrelevance result is established: if a mixed oligopoly is viable, then it generates the same solution, in terms of aggregate costs, aggregate output and welfare, as an all-private oligopoly. But we also show that for this range of cost disadvantage, a monopoly public firm yields a higher level of welfare. Nonetheless, this does not necessarily mean that mixed oligopoly should be ruled out on welfare grounds.
For we have abstracted from the potential endogeneity of the cost function. Thus, for example, in practice, in the absence of competition, the costs of the public firm might drift up into the range in which all-private oligopoly outperforms each of the alternatives in welfare terms.

\section{Acknowledgment}

We are grateful to a referee for very helpful comments.

\section{Appendix. Proof of Proposition 2}

Aggregate output is a sufficient statistic here for net social welfare. From (4), the output of a monopoly public firm is [ $a-$ $\left.c^{0}+\sqrt{\left(a-c^{0}\right)^{2}-4 k^{0}}\right] / 2 \equiv \bar{q}^{s}$. From (12), the aggregate output of a mixed oligopoly is $q^{s *}+n^{*} q^{p *}=a-\sqrt{k^{p}}$. It is found that

$$
\begin{aligned}
& {\left[a-c^{0}+\sqrt{\left(a-c^{0}\right)^{2}-4 k^{0}}\right] / 2 \gtreqless a-\sqrt{k^{p}} \text { as }} \\
& c^{0} \lesseqgtr \sqrt{k^{p}}-k^{0} /\left(a-\sqrt{k^{p}}\right) .
\end{aligned}
$$

But, from Lemma 1, a mixed oligopoly is only viable for $c^{0} \leq \sqrt{k^{p}}-$ $k^{0} /\left(a-2 \sqrt{k^{p}}\right)$. Since $\sqrt{k^{p}}-k^{0} /\left(a-\sqrt{k^{p}}\right)<\sqrt{k^{p}}-k^{0} /\left(a-2 \sqrt{k^{p}}\right)$, it follows from (A.1) that, for $c^{0} \leq \sqrt{k^{p}}-k^{0} /\left(a-2 \sqrt{k^{p}}\right), \bar{q}^{s}>$ $q^{0 *}+n^{*} q^{p *}$. Therefore a monopoly public firm yields greater social welfare than a mixed oligopoly (or an all-private oligopoly (given Proposition 2)).

For $c^{0} \in\left(\sqrt{k^{p}}-k^{0} /\left(a-2 \sqrt{k^{p}}\right), a-2 \sqrt{k^{0}}\right]$ a mixed oligopoly cannot obtain, but a public firm monopoly is viable, while, for an all-private oligopoly, aggregate output $\hat{n} \hat{q}^{p}$ is still $a-\sqrt{k^{p}}$. A parallel argument applies to that given above. Using (A.1) and the inequality $\sqrt{k^{p}}-k^{0} /\left(a-\sqrt{k^{p}}\right)<\sqrt{k^{p}}-k^{0} /\left(a-2 \sqrt{k^{p}}\right)$, we find that $\bar{q}^{s}<\hat{n} \hat{q}^{p}$.

\section{References}

Bennett, J., La Manna, M., 2012. Mixed oligopoly and entry. CEDI Discussion Paper $12-02$.

Crémer, H., Marchand, M. Thisse, J.-F., 1989. The public firm as an instrument for regulating an oligopolistic market. Oxford Economic Papers 41, 283-301.

Estrin, S., de Meza, D., 1995. Unnatural monopoly. Journal of Public Economics 57, 471-488.

Florio, M., Fecher, F., 2011. The future of public enterprises. Annals of Public and Cooperative Economics 82, 361-373.

Ghosh, A., Mitra, M., 2010. Comparing Bertand and Cournot in mixed markets. Economics Letters 109, 72-74.

Ino, H., Matsumura, T., 2010. What role should public enterprises play in free-entry markets? Journal of Economics 101, 213-230.

Matsumura, T., Kanda, O., 2005. Mixed oligopoly at free entry markets. Journal of Economics 84, 27-48.

Matsumura, T., Ogawa, A., 2012. Price versus quantity in a mixed duopoly. Economics Letters 116, 174-177.

Roland, G. (Ed.), 2008. Privatization: Successes and Failures. Columbia University Press, New York.

White, M.D., 1996. Mixed oligopoly, privatization and subsidization. Economics Letters 53, 189-195.

\footnotetext{
2 Although Proposition 1 generalizes to cover increasing marginal cost, Proposition 2 does not. This is because increasing marginal cost creates a bias against a single firm (public in this case) compared to $n$ (private) firms, for $n>1$.
} 